\title{
The use of scientific knowledge in the decision making process of environmental public policies in Brazil
}

\author{
Maria José Carneiro, Teresa da-Silva-Rosa
}

\begin{abstract}
The way policy makers mobilize scientific knowledge in order to formulate environmental policies is important for understanding the developmental process of environmental policies. Some biodiversity conservation policies, such as those establishing the conservation units and laws on the regulation of land use in protected areas, were selected as objects of analysis. The aim was to see whether political decision makers are supported by scientific knowledge or not. Based on interviews with technical staff from governmental institutions, politicians and scientists, this study analyzed the way the knowledge is mobilized by policy makers concerning measures related to biodiversity conservation in the state of Rio de Janeiro (Brazil). We have concluded that environmental policy makers do not normally use the knowledge produced by scientific and academic institutions. Rather than being based on a systematic bibliographic research on environmental issues, the decisions are supported either by personal experience or by expert advice. The measures under analysis were not supported by evidence based on knowledge but motivated by political or economic interests. Paradoxically, policy makers consider themselves sufficiently well informed to make decisions concerning the policy to be implemented.
\end{abstract}

\section{Introduction}

Despite the growing importance of the Brazilian scientific production in areas related to biodiversity ${ }^{1,2}$ and the amount of environmental policies dealing with biodiversity conservation, serious environmental problems derived from the high rates of habitat destruction in Brazilian biomes are not mitigated (Scarano, id). Most of the time, the environmental damage is due to the way economic activities use natural resources, such as agriculture.

In this context, the debate on the relationship between society and nature unfolds itself, with special attention to the formulation of policies concerning the impact of human activities on the environment. One of the questions which ignite this debate is related to the role of agriculture in biodiversity conservation and that of the local population in public protected areas. In order to support their positions, decision makers resort (or should do) to any kind of scientific knowledge produced and made available through different means. Thus, we believe that the communication between scientists (in other words, their scientific production) and policy makers is one valid way to understand how science can be useful to public interests.

Based on this debate, a group of researchers from different academic backgrounds designed the research project Agriculture and sustainable development in the problematic of 'Public Policies based on evidence' which involves case studies in France, Brazil, and South Africa. ${ }^{3}$ It aimed to examine how the empirical validation of knowledge mobilized during political action is effectively explained, evaluated, and taken into account by public policy makers. The starting point was to analyze how (and whether) policy makers access sources and scientific data effectively in order to create specific policies or measures that regulate biodiversity conservation. This research project is based on the assumption that the formulation of environmental public policies in some way draws on scientific knowledge for validating, justifying and legitimizing decision-making by directly mobilizing either specialists or the available bibliography.

Considering this scenario, this article aims to present and discuss the results of a case study developed in Brazil dealing with biodiversity conservation measures in the Atlantic Rainforest biome. It consisted in identifying: (a) the knowledge mobilized by policy makers to formulate environmental measures; and (b) the 
procedures used to access it in order to support their decisions. The initial hypothesis in this research is that access to knowledge can be useful to wider the range of choices $n$ the decision making process.

For this purpose, three environmental measures were chosen in order to guide the identification of people involved in the decision making process: one national environmental act, the Atlantic Forest Law which is under the responsibility of federal bodies; and two conservation units both in a key environmental area in the Rio de Janeiro State (Brazil). They are: the Três Picos State Park and the Macaé de Cima EPA which are administered at the State level by, nowadays, the Institute of Environment (INEA/RJ), responsible for the execution of the forestry and natural resource conservation policy in the Rio de Janeiro State. Representing different geographical levels of implementation, these conservation measures would enable an analysis at the state and federal levels.

We shall begin our argumentation by presenting some aspects related to the general debate on the bridge between Science and Policy. Then, we present a summarized characterization of the chosen conservation measures taking into account their importance for the conservation and use of natural resources in a Brazilian mega diverse area: the Atlantic Forest. Afterwards, we shall discuss four issues raised by the interviewees: a) the kind of knowledge mobilized in the elaboration process of the selected environmental measures, which is the object of the analysis; b) the relationship between science and politics; c) the form of access to knowledge and information sources required to create such instruments; d) the place reserved by interviewees for social issues, particularly those affecting small family farmers.

\section{Background}

In the field of academic production, Bruno Latour (1995), ${ }^{4}$ Philippe Descola (2003), ${ }^{5}$ Tim Ingold (2000), ${ }^{6}$ among others, have, each in their own way, engaged in efforts to propose alternatives to the approaches of Social Sciences concerning the relationship between nature and society. How to understand the relationship between Humankind and the environment without getting trapped in dualistic interpretations which have long since dominated this debate, especially in the field of the Natural Sciences considering their huge influence over political decision making as shown in our research? Although it entails numerous controversies, this debate contributes towards thinking about the way Social Sciences has been incorporated into the environmental issues.

Compared to the contribution of the natural scientists, the late interest of Social Sciences in environmental issues ${ }^{7}$ is evidenced by scientific bibliography. ${ }^{8}$ It is acknowledge that the Social Sciences, in responding to social demands, have evolved emphasizing social variables, while neglecting the key aspect of natural variables as a reaction to natural explanations. ${ }^{9,10}$ In fact, this has become a difficulty for social scientists when approaching complex and interdisciplinary issues such as environmental ones. Consequently, this might have contributed to the late interest of social scientists regarding environmental problems ${ }^{11}$ and, additionally, limited the contribution of Social Sciences in understanding contemporary environmental problems up until the United Nations Conference on Environment and Development, in Rio (1992).

The emptiness left behind by the Social Sciences in the environmental debate was occupied by natural scientists, who have acquired an interest in it not only regarding purely academic concerns, but also regarding political issues and related social issues. ${ }^{9,11}$ This, in association with the reification of the duality between nature and society, might offer some clues towards explaining the disregard for the contribution of social scientists by decision makers in the environmental field.

In Brazil, Social Sciences became more interested in the environmental problems from the moment it became an issue for society, turning it into a sociological problem, ${ }^{12}$ mainly after the Rio Summit, in 1992. Nevertheless, environmental decision makers continue to treat environmental problems through the lenses of the Natural Sciences, specially, Biological Sciences. An expression of this was the scarce participation of social scientists in a seminar organized by the Ministry of the Environment in 2007 to discuss ways of bringing the political power (policy makers) and the scientific community closer together, in order to create the means to accelerate the sharing of knowledge between both spheres. ${ }^{13}$ Among the thirty representatives of various academic institutions, we identified only three social scientists. As one can imagine, the debate was focused on issues related to the natural sciences.

In this context, the bridge between science and policy is another aspect that may contribute to the decision making process. However, even in the field of the Natural Sciences, the dialogue between scientists and political actors seems to be far from adequate. Concerned with the effects of the distance 
between scientific research (including the production and access to accumulated knowledge) and political practice, ${ }^{14}$ some governments (mostly the British and American governments) have made attempts to support their political decisions with more precise information from an empirically validated research method known as Evidence-Based Policies. ${ }^{15},{ }^{16}$

Mainly, this approach is more usual in areas such as health, education, justice, social assistance. Based on experiences in the field of Medicine, researches have revealed that therapeutic decisions were made, more often than not, in accordance with medical practices than with validated knowledge; and many new medical technologies were adopted based on pressure by the public and by laboratories rather than on their efficiency. This resulted in the establishment of a system for disseminating information, which facilitated the access to scientific knowledge by doctors. Since then medical practices can be based on scientific evidences also.

From this experience, researchers defend that environmental conservation policies fall into the same mistake, that means, a large amount of the decisions are not based upon evidence, rather on personal accounts. ${ }^{17}$ In this way, a debate started, which is currently very intense, on the possibility of applying this evidence based methodology with the purpose of improving the efficiency of environmental policies through providing an adequate access to scientific information by policy decision makers regarding the conservation of natural resources. ${ }^{18}$ Nevertheless, this approach is still very unusual in interdisciplinary fields like the environmental one where the search for the sustainability of economic activities and the biodiversity conservation fare together.

The use of this knowledge is, however, problematic taking into account its diversity, mainly related to environmental issues when compilers can have access to a variety of knowledge sources - from Social to Natural Science - in order to serve as basis or as a framework to policies. Besides that, when Politics search for certainty, Science is mostly sustained by controversial or contested empirical arguments, mainly in the case of Social Sciences. In this sense, the hypothesis that such controversy is not acknowledged by decision makers, nor is it assessed regarding the empirical evidence of scientific arguments is taken into consideration. Furthermore, regarding the late interest of Social Science in environmental issues, compilers and policy makers would be more akin to mobilize knowledge produced by the Natural Sciences. We presuppose that other factors are taken into account when selecting one or another scientific argument regarding the same issue.

\section{Research methodological procedures}

Brazil is a mega diverse country where the Atlantic Forest biome stands out for its high rates of endemism: out of twenty thousand plant species approximately 8,000 are endemic, which corresponds to $2.7 \%$ of the worldwide rate of vegetal species. For this reason it is considered as the fourth most important hotspot among the 25 hotspots in the world. ${ }^{19}$ Stretching along the Brazilian coast, the Atlantic Forest, after 500 years of colonization, has been reduced to 7.26 per cent of its original area. ${ }^{20}$ The Rio de Janeiro State (Brazil) is characterized by a historically strong human intervention, which has caused a lot of damage to this biome: it is estimated that, in 2000, the Atlantic Forest area merely corresponded to 16.73 per cent of the State. The two conservation unities studied here have a fundamental role in the conservation of the Mata Atlântica biome as they enable the connection between existing conservation units in the State.

The Três Picos State Park is the biggest one in Rio de Janeiro (46.600 ha). It is considered of great ecological interest for having rare and endemic species, but also because it protects springs that are extremely important for the whole region of the Guanabara Bay basin. It is an integral protection unit which only allows indirect use of its natural resources such as scientific research and tourism. The Macaé de Cima Environmental Protection Area (7.000 ha) has its origin from an Ecological Reserve created as a result of pressure by botanists and researchers from the Botanic Garden of Rio de Janeiro. Contrarily to the park, it is a sustainable use unit that allows the development of economic activities by the local population despite being submitted to several restrictions. Besides, the Atlantic Forest Act, a national law which regulates the conservation, regeneration and use of native vegetation in the whole area of this biome including the above conservations units, was also object of this study.

It is also important to notice that the establishment of a conservation unit has an impact on the surrounding area, on its buffer zone, where human activity is subjected to specific norms and restrictions, with the purpose of minimizing negative impacts on the unit. Agriculture is not the most important 
activity in the State of Rio de Janeiro. However, the region of both conservation units is mainly involved with the production of vegetables, fruits and farm products, because of its proximity to the State capital, Rio de Janeiro city, a big consumer market. Therefore, the implementation of these conservation measures can cause conflicts between the various interests of local actors, particularly between the public bodies and the local farmers.

It was difficult to identify or find professionals having taken part in the decision-making process of all three measures due to various reasons such as: a very long decision making process, bringing about many debates; and changes at the government sphere or at the public bodies during this time. The Atlantic Forest Law can illustrate this obstacle. It is an outcome of an intense political debate, which went on for 14 years as a response to a social demand involving many segments of society (deputies, NGOs, members of social movements and scientists). Some of the people involved in the whole process could be identified and were contacted for interviews.

A structured questionnaire was applied to the interviewees. Its questions guided the interviews which were, firstly, recorded and, then, transcriptions were made. Twenty eight people were interviewed, divided in three general categories: (1) Most of the people interviewed were or still are, professionals, connected to the public environmental bodies at the federal, state and municipal levels $(n=17 / 28)$ : conservation unity managers, technicians, civil servant managers and researchers; (2) representatives of nongovernmental organizations: associations gathering local inhabitants, small farmers' and environmentalists' (n=8/28); and (3) federal deputies involved in the process of formulation of the federal Atlantic Forest Act. The qualitative analysis was privileged considering this interviewed universe for his study.

\section{Results and discussion}

\subsection{Mobilized scientific knowledge}

The central question here is to understand how scientific knowledge is accessed and used by technicians and policy makers involved in the decision making process of the three selected measures. In order to achieve this goal, we made use of deal with the interviews with social actors involved in the process of elaborating those environmental measures. Two important aspects are pointed out: (a) how knowledge is frequently used in order to justify or sustain the environmental measures under study; and (b) the different fields of knowledge mobilized.

Related to the establishment process of the Conservation Units, the access to scientific information occurred only after their creation. And this was done in order to comply with bureaucratic requirements. That means that the use of scientific knowledge was an important instrument for legitimizing political positions that were usually already established prior to the access to scientific information. On the other hand, in the case of the Atlantic Forest Act, the political debate was mediated by the scientific debate (through workshops and expert consultancies) throughout the long (14 years) negotiation process. Despite interviewees have affirmed that they made use of specialized bibliography occasionally, none could quote any scientific reference as an example, but just books on general subjects on ecology. In order to access specific information their preference was given to direct consultancy with specialists through workshops organized by environmental NGOs or even through personal contact with scientists.

In relation to the different scientific areas of knowledge that were mobilized, the most frequent one is that from the natural sciences particularly botany. In general, public policy managers, scientists, and technicians involved in the environmental questions believe that biodiversity is an issue that affects only "nature" since nature is understood as a realm separated from society, which can explain the lack of interest in other sources of knowledge besides the natural sciences.

The demanding for social science is rare or uncommon; however, the concern with social issues was more present among the technicians who were more involved in the implementation of conservation units in contrast to those who participated in the formulation process of public measures. This "social" concern is due to the fact that those civil servants involved in the implementation activities - and, most of the time, engaged in conflict management - are led to focus their attention on social relationships and crises, which are mainly noticeable at the local level. These different views on the role of social issues in the realm of biodiversity conservation inform the type of mobilized knowledge. In general, during the creation process of a conservation unit, the knowledge accessed is exclusively from the field of natural 
sciences. When a conservation unit is perceived through the perspective of territorial management, some references to concepts and notions of social sciences are noticed, for example, the need for sociological knowledge when dealing with social conflicts or anthropological reports to sustain the creation of conservation areas inhabited by the "traditional population". 21

Certain concepts from the Natural Sciences are used in a recurring manner, which suggests the incorporation of a knowledge that went through a process of scientific legitimating and political persuasion resulting in a consensus. This is the case of the frequent references to notions such as "mosaic of conservation units", "ecological corridor", and "watershed", which end up guiding decisions. These consensual notions are considered as being self-evident, as they are hegemonic notions or principles that are above any controversies common to the scientific practice. However, this use of scientific notions into technical purposes is not based on a systematized search for the available knowledge. Contrarily, they are information and notions that are appropriated through their professional experience and their academic background. This can justify why most of the interviewees could not recognize the origin and the author of the knowledge sustaining their formulations.

Some knowledge has been inculcated as technical consensus without an accurate treatment or evaluation regarding their definition and techno-scientific grounding. We can refer to this as an "established truth", which, is not necessarily submitted to scientific procedures. Thus, what is at stake is not whether that knowledge is empirically grounded or not. Rather, regarding the use of scientific knowledge by public policy makers, what is on the agenda is the displacement of certain notions from their original scientific formulation and application in other contexts resulting in different senses. This can be perceived in the speech of an interviewee, who, at the time, was a member of the techno-political board of the State Secretariat for the Environment in Rio de Janeiro: "This is what I usually say: you do not have to be an expert to look at the map of Rio de Janeiro and see the need to preserve that kernel, you only need to look" (pointing at a great green spot in the map on the wall in front of the interviewers).

It is also possible to observe from the responses given by the interviewees that there is a common understanding that the knowledge acquired through their professional experience and commitment to the environmental cause is more important than the theoretical knowledge made available by means of the scientific literature. The same person quoted above is an example when he says: "...everyone who is, one way or another, involved [in the creation of the Park] has already had a lot of experience with the conservation unit issue. From that moment on you already have a great identity of thought; you don't waste much time with theoretical discussions regarding this issue".

On the other hand, Latour helps us understand that the production of scientific evidence - the "fact" - is the result of a social construction process within the scientific community, reminding us that this process results in the social acknowledgment (always temporary) of the researcher. Moreover, the "fact" is incorporated into practices and instruments (when it turns into a consensus) and it disappears as a result of a scientific construction process. ${ }^{4}$ The collective nature of this construction - and the volatility of the fact as evidence - implies the impossibility of demanding the authorship of this knowledge. The remarked difficulty of interviewees in identifying works and authors that were a reference to their decision-making processes in political practice is, thus, understandable. In this sense, it becomes hard to separate scientific concepts and political notions, since the first is operational through a process of incorporation of knowledge in the political practice.

The predominance of this empirical-pragmatic view is corroborated by the absence of demand for a more technically grounded document, which may sustain the request for creating a Conservation Unit, at least at the level of the policy making process in the Rio de Janeiro state. Usually, the main document of this process - called "technical justification" - must be short and general, "otherwise no one will even read it", as it was remarked by a technician from the Rio de Janeiro State environmental office. The underestimation of this document as a means to present scientific arguments (essentially from the natural sciences) reveals the preference for the persuasion strategy based on the political negotiation preceding decision-making. Greater importance is given to the sense of opportunity, that is, the adequate political timing to present a demand for creating a Conservation Unit. However, the concern with scientific grounding is more present at federal level.

However, although science and politics come together in the formulation process of environmental measures or policies, there is tension in the relationship between scientists and decision makers. As an example, when scientists insist in explaining their "neutral" stance regarding politics: "I [scientist] produce information, which can stay inside a specialized library, or, by chance, reach the hands of an 
interested technician, or even be disseminated if there is dialogue, etc., and assist the technician who would be responsible for (those) areas, request a feasibility study...". On the other hand, the decision makers tend to underestimate the "scientific" approach side, by accusing it of "academicism" and "disengagement from reality", while scientists refer to technicians as "frustrated scientists". This tension undoubtedly explains and reinforces the deep gap on the communication between politics and science, at least regarding the biodiversity issue in the fields studied.

\subsection{Bridging science and politics}

In analytical terms, it is possible to recognize four modalities of the relationship between the scientific and the political spheres: 1) when politicians search for a "scientific" grounding to justify their propositions and provide them with greater legitimacy; 2) when scientists instrumentalize their knowledge in order to adapt it to political application; 3) when "scientific knowledge" is subjected to political interests; 4) when science is also seen as a political arena where scientific paradigms dispute for legitimacy in politics.

\section{Science legitimizing politics}

In practice, the interest in knowledge on the part of the governmental sphere is usually oriented by the need for legitimizing policies. The federal congressman interviewed highlights the fact that the Intergovernmental Panel on Climate Change /IPCC is an example that "science determines virtually all definitions of statesmen". The political use of consensual scientific knowledge throughout their reports ignited, updated and affected the debate about the relationship between science and political decisions. However, says the congressman, "one cannot be reduced to the other: although "scientific formulation is supported by data" (which echoes the idea of truth), "their suggestions must be submitted to a political process of persuasion" and "the question for politicians is exactly to see how you can put into practice what you have there. In that case [of global warming], we [politicians] virtually depend on research to formulate the path of countries".

In general, autonomy between the two fields is recognized, but, at least ideally, the governmental sphere is considered to depend on scientific knowledge. Here, it is possible to identify the concern with communication between the two spheres, alerting to the difficulty of implementing formulations based on scientific evidence in the political practice. This is an important aspect because it clearly states that a good scientific basis is not enough for policy effectiveness, since another dimension overlaps the validity of scientific arguments: the dimension of negotiations in the political arena. The submission of facts to political grounding must be considered: "A scientist or environmentalist arriving in the National Congress by himself cannot be successful", says an interviewee from the technical staff of the Ministry of the Environment, in the sense that the political weight of his/her argument will depend less on evidence sustaining it and more on who supports it: whether it is a scientific association, such as the Brazilian Society for the Progress of Science (SBPC), or a notorious scientist whose legitimacy is unquestionable.

\section{Instrumentalizing science through politics: think tanks and collective production}

The second modality of communication between science and politics aims at combining the exiguity of time for political decisions with the diversity and scope of available knowledge on a specific subject. This challenge is usually met through workshops where scientists gather in order to systematize already existing and credible knowledge, ${ }^{22}$ although there are other mechanisms, such as: public calls for finance research launched directly by the Ministry of the Environment on subjects of interest to the government; or the establishment of commissions formed by experts, representatives from scientific societies, from the government and sometimes from the civil society.

Through the discussion between their participants, these workshops intend to elaborate summaries, and build up a consensus on issues suggested by the political sphere. Mostly, they are mediated by nongovernmental organizations, which select "their own" scientists ${ }^{23}$, legitimizing then a certain scientific knowledge. In this way, knowledge is processed and delivered, which helps its technical appropriation by the political practice. Thus, workshops are elected as the place where scientific knowledge on a particular subject is consolidated in order to collaborate closely to and to assist decision makers. This is an easier, 
cheaper and time-saving way to access the existing knowledge and also the one acquired through professional experience. Despite the participation of several scientists, the knowledge which is systematized in these events differs from the strictly called "scientific knowledge". These arenas are think tanks where knowledge is "processed" and adapted to the needs of political sphere and translated to the language of the policy makers political sphere. In this process, individual knowledge is gathered, transformed, and summarized into "collective knowledge", which, therefore, does not have a single author.

\section{The place of science in political negotiations}

Workshops are also an arena of dispute and negotiations of interests. It is clear that decision-making depends more on the political interests at stake than on knowledge sustaining its scientific grounding. The quality of the scientific argumentation is worthless if it is not in accordance with political interests. It may happen that the official political interests exist prior to scientific justification, prevailing over it, as in this statement: "first, we make the decision and then we find a scientist to support us", said some of the interviewees of the governmental level. Corroborating this idea, the same statement was made by an interviewee from the opposite side of the issue - a scientist and consultant: "first they [politicians] decide, and then they call us".

\section{Scientific paradigms dispute political legitimation}

If we take for granted that the scientific field creates an illusion of knowledge as being "uninterested", and dominated by the "interest for the absence of interest", ${ }^{24}$ this present study reveals how "absence of interest" gets interested in the political dispute. If we agree with Bourdieu that in the economy of symbolic goods, as in the scientific field it is the absence of interest that offers "compensation", in the political realm it is the interest that offers a compensation and sets the disputes going. However, if the absence of interest is considered an illusion (illusio) we can perceive, in the dispute over the selection of knowledge that will be legitimized (by the political instance), the ambiguity which is present in the behavior of scientists who defend both neutrality and commitment with the reality. This ambiguity, we can say, is not supposed to be a characteristic of one or another scientist, but a feature of the scientific field itself.

We can observe here the limits of the scientific grounding in the political decision making. The controversies or queries, characteristic of the scientific knowledge production, are used in such a way as to favor opposite sides of the dispute, which ends up resulting in a draw, in other words, in a neutralization of both parties, since both offer equally "scientific" arguments.

\subsection{Policy makers' access to sources of knowledge: limits of communication and facilitating elements}

The communication between Sciences and Politics is not simple as it involves various limiting aspects, such as language and objectives specific to each field. ${ }^{22}$ In this topic, we shall deal with these elements as well as with some mechanisms created to resolve these limitations.

\section{Difficulties of communication}

Both public policy managers and researchers agree that the limits of this communication are due to three elements, all of them related to the difference between their specific skills.

A great barrier to this communication is the language. It is common to hear complaints from managers about the difficulty in understanding scientific texts: "scientists write for other scientists"; "politicians don't know the technical terms employed by scientists". In their turn, scientists recognize that language draws them away from a wider public, which hinders the application of produced knowledge. Moreover, there is a distinction between their attitudes regarding the use of information. While science evolves through the debate caused by doubts and controversies, decision makers or politicians work with consensus and certainty, defined as the "culture of apparent agreements". 1

Another obstacle is the time necessary for the production of new knowledge - and even for accessing the knowledge already produced - which is not compatible with the time of political practice. From the perspective of decision makers, the constant and urgent political commitments which may pave the way 
for their decisions, do not coincide with the time needed to produce scientific knowledge, to research bibliographical registers and to subsequently read scientific articles ${ }^{25}$.

The disconnection between the way science produces knowledge and the social or political demands is also a limiting aspect. that are to be transformed into public policies. Normally scientific researches deal with very specialized objects which cannot be directly used by policy makers, making the appropriation of scientific knowledge for public purposes more difficult. Contrarily to Latour's idea (1995), ${ }^{4}$ which brings science and politics closer together, scientists gathered at a government consultation, recognize a difference between their motivations. Among scientists, more strictly individual interests are perceived (one could say "free from ideological pollution", according to Latour's view), while decision makers are perceived as more engaged in collective interests, "from society".

\section{Strategies for facilitating communication}

One strategy for facilitating the bridge between science and the policy process is the direct access to experts through the workshops mentioned earlier and personal relationships which is very often used in order to answer the demand for information from the government. In general, these experts are recommended by Brazilian scientific societies, they are icons within a particular issue, or they have public recognition and receive media exposure or even if they are more available for this kind of consultation.

Additionally, there is a lack of information on existing sources. Although internet is generally accessed, the use of digital databases of any Brazilian academic sources, ${ }^{26}$ such as those providing open access, is rare, exception of those interviewees having post-graduation background.

Even though a good deal of the references on researchers and abstracts of their research is available in the existing database on the internet page of the Brazilian National Council for Scientific and Technological Development $(\mathrm{CNPq})$, the access to it was not mentioned by any of the decision makers interviewed. At the most, there was mention of the pages related to the entities responsible for policy administration (the Ministry for the Environment, for instances), and mostly for reasons of updating legal and normative regulations concerning intervention and regulation instruments related to the object and/or to the study area of our project.

\section{Conclusion}

The communication between Politics (policy makers and managers) and Science (scientists and the produced knowledge) is a very important issue, mainly to better understand the role of the latter in the environmental policy making process in general, and in biodiversity conservation policies in particular. One way to understand this communication is studying the access and the use of scientific knowledge by compilers or decision makers in order to support their positions in political debates and by those dealing with the implementation of environmental measures in areas historically occupied.

This study has revealed that the access to and the use of scientific knowledge is needed, but discrepancies were observed which can drive our attention to the need for questioning if the use and access to knowledge as practiced by the interviewees would be useful to wider the range of choices in the decision making process. This remark can be supported by several facts: there is not a culture for a systematic searching on the existing online database; the search for scientific knowledge is timeconsuming considering the time of the decision making process; few observed experiences on communication between decision makers and scientists (or scientific knowledge) are isolated and non systematic; and questions made by Science and Politics are not the same, resulting a gap in the communication between both fields.

Moreover we have seen that the decision making process is much more based on the personal experience of the technicians working at local governmental environmental bodies than on a survey about the existing sources. When the access to internet is done, there is no concern about the feasibility of the information. Nevertheless, the use of scientific knowledge is considered important as a relevant legitimating factor in the dispute taking place at the stage of negotiation and decision.

Finally we would like to draw attention to the lack of methodological parameters in the process of accessing knowledge. Since the practice of using systematized search systems, with specific methodological parameters is not established, a great deal of fortuity dominates the process of obtaining 
information. This suggests a very important issue: which institution would be responsible for facilitating the dissemination and the access of scientific knowledge by the political sphere? Attempts have been made, such as the establishment of professional Masters, aiming at training professionals from certain scientific areas to employ scientific knowledge in other fields such as governmental institutions, private enterprises, social movements, etc.

Another possible alternative is given by the evidence based methodology in the policy making process: the setting up of collective structures responsible for inventorying scientific knowledge on specific issues and then producing a systematic review (a meta-analysis) which is going to support policy-makers in their decisions. This is the case of the Centre for Evidence-Based Conservation ${ }^{27}$ (UK). In regards to this matter, we should mention two Brazilian initiatives which tackle biodiversity in a broader sense: (1) The Centre for References on Environmental Information (Referência em Informação Ambiental ${ }^{28}$ - CRIA) aims to promote electronic information as a tool for the scientific and technological community in the country. However, this database and its projects are strongly oriented to the; (2) the Brazilian Portal on Biodiversity/PORTALBio ${ }^{29}$ of the Ministry of the Environment which aims at promoting production, dissemination and exchange of information on conservation and sustainable use of Brazilian biodiversity. Within the scope of our study, however, no interviewees mentioned any of these sites. More recently (2010), the Brazilian government together with some public research institutions have created the database BHL Scielo (http://biodiversidade.scielo.br) to managing information and scientific knowledge on biodiversity.

Thus, we are aware of the fact that the conclusions and comments presented here can not be generalized as a valid standard for all and any situation of public policy formulation in Brazil. Given the diversity in the universe of Brazil and the limitations of the object of our research, we must emphasize that we are discussing only one of many cases in Brazil.

\section{Acknowledgement}

We are grateful to the Brazilian National Council for Scientific and Technological Development $(\mathrm{CNPq})$, the Rio de Janeiro State Research Foundation (FAPERJ) for the research grants to Maria José Carneiro and to French National Research Agency (ANR) for the financial support.

We are grateful also to Luciana Lang for her translation work.

\section{Notes and references}

F. Scarano (2007), Perspectivas das ciências da biodiversidade no Brasil, Sci. Agric. 64: 439-447.

Brasil (2008), Ministério do Meio Ambiente e Ministério da Ciência e Tecnologia. National consultation meeting for creating a scientific advisory mechanism, regarding policy decisions on the scope of the convention on biological diversity and the Brazilian government, Final Report. Brasília, January 2008.

3 C. Laurent (2006), Agricultura e desenvolvimento sustentável nas problemáticas das 'Políticas baseadas em evidencias', Projeto de Pesquisa, INRA, Paris France.

4 B. Latour (1995), Le métier de chercheur regard d'um anthropologue, Ed. INRA, Paris France.

$5 \mathrm{Ph}$. Descola (2003), Décrire, comprendre, expliquer, in J-P. Changeux, La vérité dans les sciences. Odile Jacob, Paris France, pp 81-92.

${ }^{6}$ T. Ingold (2000), The perception of the environment - essays in livehood, dwelling nd skill, Routledge, London U.K.

7 The notion of environmental sociology first emerged in the 70's, as remarked by Hannigan (2009). ${ }^{10}$

${ }^{8}$ See Leis $(2001)^{9}$ and Büscher and Wolmer $(2007)^{32}$

9 H.R. Leis (2001), Para uma reestruturação interdisciplinar das ciências sociais: a complexa tarefa de enfrentar os desafios da problemática ambiental sem cair no senso comum da sociedade civil, Ambient. Soc. 8: 145-154

10 J. Hannigan (2009), Sociologia ambiental, Petrópolis, Vozes Brasil.

${ }^{11}$ J.A. Drumond (2006), A primazia das Ciências Naturais na construção da agenda ambiental contemporânea, Rev. bras. Ci. Soc. 21(62): 5-25.

${ }^{12}$ A. Brandenburg (2005), Ciências Sociais e ambiente rural. Principais temas e perspectivas analíticas, Ambient. \& Soc. VIII(1): 51-63.

13 It was called the National Consultation Meeting for creating a scientific advisory mechanism regarding policy decisions on the scope of the Convention on Biological Diversity and the Brazilian Government, in Brasília, November 2007, in partnership with the Ministry of Science and Technology.

${ }^{14}$ Concerning this subject see Da-Silva-Rosa \& Carneiro (2010). ${ }^{31}$ 
${ }^{15}$ H.T.O. Davies and S.M. Nutley (2001), Evidence-based policy and practice: moving from rhetoric to reality, Third International, Inter-disciplinary Evidence-Based Policies and Indicator Systems Conference, July 2001.

${ }^{16}$ C. Laurent et al. (2009), Pour quoi s'intéresser à la notion «d'evidence-based policy»?, Revue Tiers Monde 200: 853-873.

${ }^{17} \mathrm{~W}$. Sutherland et al. (2004), The need for evidence based conservation, Trends Ecol. Evol. 19(6): 305-308.

18 The Centre for Evidence-Based Conservation/CEBC (University of Birmingham) has as its main purpose to be a source of evidence and to coordinate a network of collaborators in developing systematic bibliographic revisions. http://www.cebc.bangor.ac.uk/

${ }^{19}$ N. Myers et al. (2000), Biodiversity hotspots for conservation priorities, Nature 403: 853-858 www.nature.com.

${ }^{20}$ Cf. Fundação SOS Mata Atlântica e Instituto Nacional de Pesquisas Espaciais. Atlas de Florestas Remanescentes da Mata Atlântica (SOS Atlantic Forest Foundation and National Institute for Space Research, Atlas of the Forest Remnants of the Atlantic Forest) - period 2000-2005, 2008.

${ }^{21}$ The National System of Conservation Units (SNUC, 2004), ${ }^{30}$ which was set up in the year 2000, recognizes the rights for segments of the dwelling population identified as traditional population to remain in protected areas and to perform activities of self-subsistence as long as they contribute towards the sustainable use of the natural resources and cause no harm to the environment. This regulation spawned reactions from different groups residing in such areas who started to claim their rights, which, in turn, brought about situations of conflict with environmental bodies. Besides, the notion of "traditional or local population" arose a very vivid and controversial debate during the elaboration process of this federal act.

22 J. Young (2005), Research, policy and practice: why developing countries are different, J. Int. Dev. 17: 727-734.

${ }^{23}$ The access to these consultancy groups created by NGOs, or even directly by government bodies, deserves another study.

${ }^{24}$ P. Bourdieu (2004), Os usos sociais da Ciência. Por uma sociologia clínica do campo científico, Ed. UNESP, São Paulo Brasil.

${ }^{25}$ Young (2005) has observed the same difficulties concerning the communication between scientists and policy makers dealing with development policies.

${ }^{26}$ This is the case of the Brazilian National Organization for the Development of Professionals in Higher Education/ CAPES web site (http://www.capes.gor.br) which provides various open access services that promote scientific and academic knowledge. Also, there is the Scientific Electronic Library Online /Scielo site ( http://www.scielo.br) which provides an open access to a large range of journals.

27 http://www.cebc.bangor.ac.uk/

$28 \mathrm{http}: / /$ www.cria.org.br/

29 http://www.mma.gov.br/sitio/index.php?ido=conteudo.monta\&idEstrutura=72

${ }^{30}$ SNUC (2004), Sistema Nacional de Conservação da Natureza - SNUC: lei 9985, 18 julho 2000. 5 ed. Brasília: MMA/SBF.

${ }^{31}$ T. Da-Silva-Rosa and M.J. Carneiro, O acesso livre à produção acadêmica como subsídios para políticas públicas: um exercício sobre o Banco de Teses da CAPES, História, Ciências, Saúde 17(4): 955-974.

${ }^{32}$ B. Büscher and W. Womer (2007), Introduction The politicas of engagement between biodiversity conservation and the Social Sciences, Conservat. Soc. 5(1): 1-21.

\section{Authors}

Maria José Carneiro. Anthropologist, full professor of the Social Sciences Post-graduation Program on Development, Agriculture and Society/CPDA/. Universidade Federal Rural do Rio de Janeiro. Coordinator's research group Ciência, Natureza, Informação e Saberes/CINAIS, Researcher of CNPq (National Research Council). E-mail: mjtcarneiro@gmail.com.

Teresa da-Silva-Rosa. Full Professor of the Post-graduation Program on Social Sciences, Vila Velha University Centre/UVV (Espírito Santo/ES), Coordinator's research group Expansão Urbana, questões socioambientais e políticas publicas. E-mail: tsrosaprof@yahoo.com.br.

How TO CITE: M.J. Carneiro and T. da-Silva-Rosa, The use of scientific knowledge in the decision making process of environmental public policies in Brazil, Jcom 10(01) (2011) A03. 